\title{
A novel approach to minimally invasive hysterectomy without the use of a uterine manipulator: Kamran's TLH technique
}

\author{
Ahmed M. Gendia* (D), Noel E. Donlon and Waseem M. Kamran
}

\begin{abstract}
Background: There are a number of techniques documented in the literature to perform laparoscopic hysterectomy, and here, we propose a safe and novel technique that obviates the need for a pelvic assistant, removes the need for a uterine manipulator and can potentially reduce operative duration.

Results: Total laparoscopic hysterectomy can be approached without the use of uterine manipulator or vaginal tubes using the steps demonstrated.

Conclusions: This novel technique is safe, efficient and conducive to standardising minimally invasive hysterectomy practices obviating the need for a uterine manipulator and pelvic assistant.
\end{abstract}

Keywords: Kamran's TLH, Uterine manipulator, Hysterectomy, LTAH, Laparoscopic surgery

\section{Highlights}

- This video outlines surgical steps to perform total laparoscopic hysterectomy without the use of uterine manipulator.

- This technique can safely be applied in both malignant and benign hysterectomies.

- It can also help to reduce operation time and the need for pelvic assistant.

\section{Methods}

Surgical steps are as the following:

1- The Vagina is loosely packed with a sterile swap wrapped in a sterile glove.

2- Traction on the broad ligament is applied, and the infundibulo-pelvic ligament is coagulated and transected. This can be achieved with or without opening the pelvic side wall. Same step is repeated on the opposite side.

* Correspondence: agandia@live.com

Beacon Hospital, Sandyford, Dublin, Ireland
3- Round ligaments are coagulated and transected bilaterally, then bladder reflection is achieved.

4- Bladder peritoneum is held towards the anterior abdominal wall, whilst the surgeon dissects the uterovesical fold in a systematic fashion as demonstrated.

5- Uterine vessels are coagulated and cut on each side with further reflection of these vessels.

6- Traction on remnant of round ligaments is applied bilaterally to bring the uterus to anterior abdominal wall; this will help the surgeon to dissect the uterosacral ligament.

7- Dissection of uterosacral ligament is continued till the line of demarcation between vagina and cervix is evident as highlighted.

8- Colpotomy, close to the cervical edge, is performed either anteriorly or posteriorly.

9- Specimen is delivered vaginally.

10- Closure of the vaginal vault.

\section{Discussion}

Hysterectomy remains one of the most common major surgical interventions in gynaecology. Since the introduction

\section{Springer Open}

(๑) The Author(s). 2020 Open Access This article is licensed under a Creative Commons Attribution 4.0 International License, which permits use, sharing, adaptation, distribution and reproduction in any medium or format, as long as you give appropriate credit to the original author(s) and the source, provide a link to the Creative Commons licence, and indicate if changes were made. The images or other third party material in this article are included in the article's Creative Commons licence, unless indicated otherwise in a credit line to the material. If material is not included in the article's Creative Commons licence and your intended use is not permitted by statutory regulation or exceeds the permitted use, you will need to obtain permission directly from the copyright holder. To view a copy of this licence, visit http://creativecommons.org/licenses/by/4.0/. 
of minimally invasive hysterectomy, several modifications have been adapted. These are laparoscopicassisted vaginal hysterectomy, laparoscopic-assisted supracervical hysterectomy and total laparoscopic hysterectomy [1]. Total laparoscope hysterectomy (TLH) has been established as a the procedure of choice among many laparoscopic surgeons, mainly because of the recent advances in minimally invasive technology and the favourable postoperative recovery [2]. Various TLH approaches have been described for both benign and malignant gynaecological diseases. These techniques are dependent on the use of uterine manipulator or vaginal tubes [3]. However, only few reports has described TLH approach without utilising either vaginal or uterine assistant [4, 5]. Kavallaris et al. described a technique of TLH without using any uterine manipulation and reported the safety of his approach, especially in patients with vaginal or cervical stenosis [5]. Also, there was no intra- or postoperative complications in all 67 hysterectomies performed in the that study [5]. Additionally, Kavallaris et al. hypothesised the use of uterine manipulator could increase the risk of spreading tumour cells in early cervical or endometrial cancer. However, a case series by Tinelli et al. compared the outcomes of laparoscopic hysterectomy with and without the use if manipulator in early endometrial cancer concluded that the use of uterine manipulator did not increase the positive peritoneal cytology or early recurrence rate [6]. Our approach demonstrates a safe, efficient and an easy to learn technique to perform TLH without the use of any pelvic manipulator. This approach can help to reduce operative time by eliminating the use of extra assistant to handle uterine manipulator and reducing blood loss by minimise any traumatic movement through vagina or uterus.

\section{Conclusions}

This novel approach is safe, efficient and conducive to standardising minimally invasive hysterectomy practices obviating the need for a uterine manipulator and pelvic assistant. Additionally, Kamran's TLH can help in reducing operative time, cost and the need for additional assistant. Moreover, studies on TLH without uterine manipulation are required to evaluate the impact on the operative time and intra-postoperative complications.

\section{Supplementary information}

Supplementary information accompanies this paper at https://doi.org/10. 1186/s10397-020-01078-z.

Additional file 1: Video
Acknowledgements

There are no special acknowledgements.

\section{Authors' contributions}

AG recorded and edited the video. NED revised the manuscript. WK supervised and revised manuscript/technique developer. All authors read and approved the final manuscript.

Funding

No funding was received.

Availability of data and materials

No data and material are available due to the nature of the study.

Ethics approval and consent to participate

Ethics approval was obtained from the local auditing committee.

\section{Consent for publication}

Consent to participate and publication in recording of the surgical video were obtained from the patient (can be provided if needed).

\section{Competing interests}

There are no conflicts of interests between the authors (forms can be provided if needed).

Received: 19 April 2020 Accepted: 4 August 2020

Published online: 25 September 2020

\section{References}

1. Elkington NM, Chou D (2006) A review of total laparoscopic hysterectomy: role, techniques and complications. Curr Opin Obstet Gynecol 18(4):380384

2. Johnson $\mathrm{N}$ et al (2006) Surgical approach to hysterectomy for benign gynaecological disease. Cochrane Database Syst Rev 2:Cd003677

3. Popa A, Copaescu C, Horhoianu V (2019) Laparoscopic total hysterectomy still not routinely chosen Operative description and available instruments. Journal of medicine and life 12(3):301-307

4. Macciò A et al (2018) Feasibility and safety of total laparoscopic hysterectomy for huge uteri without the use of uterine manipulator: description of emblematic cases. Gynecol Surg 15(1):6-6

5. Kavallaris A et al (2011) Total laparoscopic hysterectomy without uterine manipulator: description of a new technique and its outcome. Arch Gynecol Obstet 283(5):1053-1057

6. Tinelli R et al (2016) Laparoscopic treatment of early-stage endometrial cancer with and without uterine manipulator: Our experience and review of literature. Surg Oncol 25(2):98-103

\section{Publisher's Note}

Springer Nature remains neutral with regard to jurisdictional claims in published maps and institutional affiliations.

\section{Submit your manuscript to a SpringerOpen ${ }^{\circ}$ journal and benefit from:}

- Convenient online submission

- Rigorous peer review

- Open access: articles freely available online

- High visibility within the field

- Retaining the copyright to your article

Submit your next manuscript at $\boldsymbol{\nabla}$ springeropen.com 